\title{
Motivated Learners and Their Success in Learning a Second Language
}

\author{
Seyedeh Sara Jafari \\ Department of Foreign Languages, Abadeh Branch, Islamic Azad University, Abadeh, Iran
}

\begin{abstract}
This paper has tried to show how motivated students are more successful than unmotivated ones. Firstly, the word motivation was discussed in detail, and various definitions were presented. Secondly, different types of motivation and their relationship with each other were discussed. Thirdly, factors such as personality variables, attitudes towards social or cultural milieu, and non-linguistic outcomes of the learning experience and learning were discussed. Finally, some recommendations for motivating language learners were enumerated. Results show that language learning is facilitated when learners are highly motivated. Therefore, language teachers are highly recommended to motivate their learners in order to increase their chance of learning a language.
\end{abstract}

Index Terms - motivation, motivated students, personality variable, learning a foreign language

\section{INTRODUCTION}

As the term motivation itself indicates, it is a motive force, same thing that prompts, incites action. Motivation seems to be the biggest single factor affecting language learner's success. In addition, one of the factors influencing the success full of the learners in learning a $L_{2}$, is the person's motivation (Tuan, L. (2012). It is out of question that one's success in any task is closely related to his motivation. Learning a language is no exception. Learners can be motivated in various ways, by a desire, emotion, reason, need or purpose move a person to particular action. It's easy to assume that one's success in any task is based on his/her motivation, and in foreign language learning it can be claimed that a learner will be successful with motivation. The student's learning is facilitated most effectively when they are motivated, so a less able student who is highly motivated achieves greater success than the more intelligent student who is not well motivated. Being motivated is one of the most important factor in learning a foreign language (Abdelrahim, I., \& Humaida, I, 2012). Research on: Motivation to Learn English among College Students in Sudan). Many teachers and scholar in the field of language pedagogy believe that language learners will be more successful if they are motivated. Others think that motivated language learners achieve more success than the intelligent learners who are not well motivated. Sometimes, Lack of motivation is caused of low attendance, participation and performance of the students. Also motivation is accepted by both teachers and researchers as one of the factors that influence the rate and success of second / foreign language learning (Mao, Z., 2011). So, People have many different reasons for studying a foreign language, that one of them is motivation. There are many types of motivation that move people to learn, so let's see the definition of motivation, the kinds of motivation. What does it mean when we say that someone is motivated? And how do you create, foster and maintain motivation?

\section{BACKGROUND}

Some studies have been carried out about motivation, role of motivation and effect of motivation in same cases under the department of English education.

ltumaide and Abdel Rahim (2012) carried out a study on "motivation to learn English among college students in Sudan" they used questionnaire as the tool of data collection and T-test for data analyzed and also the method that they used, is descriptive and the sample is simple and random in order to select sample. The result of T-test showed that the scores of the motivation were higher among students, there was no significant difference on motivation attributed to class level, and no correlation between motivation and age were found.

Dahmardeh and Hunt (2012) have carried out research on "Motivation and English language teaching in Iran", to understanding the role of the motivation in the textbooks or the English language teaching program. In order to do so they used a desk and its linked textbooks, as the tool of data collection. They give foundation based on the result that motivation has no role in both of them (either in the textbooks or the English language teaching program) with regard to test it.

Akolkar (2012) studied on a comparative study of Achievement motivation and mental health among higher secondary students. He focused practically on relationship between Achievement motivation and mental health between male and female students, in order to understand if there is difference between their motivation and their mental health or not. He used questionnaire as the tool of data to collection and as result he found that male and female student 
significantly differ for their achievement motivation but there is no significant difference of mental health between and female student's.

Shevatekarshradavasant (2012) carried out research on the relationship between academic achievement and motivation in adolescents for investigating is there any relationship between motivation and academic achievement in adolescents or not? In order to do this research he used recording as the tool of data collection. Data was evaluated in scales that were concluded from comparing them. As result the researcher found that there is correlation between family environment and educational achievement and this correlation is positive correlation and at low level.

In another study, Tuan (2012) studied on an empirical research in to EFL learner's motivation and focused on motivation of EFL learners in order to investigate whether motivation has any impact on student's English learning or not. She uses questionnaire survey in order to collect data. Both students and teachers were involved in this survey. The result showed that the students had positive motivation toward learning of foreign language and also teachers should find necessity of motivation in developing student's English performance.

Mao (2011) has carried out a research in L2 motivation and application in reading class in senior high school to understanding the effect of motivation on learning. He used questionnaire surrey in order to collect the data and he conclude that combination of integrative motivation and instrumental motivation can exert a more influence on reading class improvement and English teachers shall take some effective application to arouse student's motivation in reading class and help them develop integrative motivation towards English learning.

Afful-Broni studied on relationship between motivation and job performance at the university of Mines and Technology, Tarkwa, Ghana: leader ship lessons have focused particularly on understanding their relationship. He used purposive and simple random sampling method. Survey was the main instrument that used in collecting data. Data collected was analyzed. With descriptive and in frontal statistic. Result of statistic showed that major reasons for reducing morale for high performance at the university, are low monthly salaries and the general lack of motivation.

Djigunovic (2012) has carried out research regarding attitudes and motivation in early foreign language learning (2012) to examine early foreign language learning attitudes and motivations. He described Approaches to studying these effective learner characteristics. His finding was presented through over views of cross sectional and longitudinal; studies which was carried out in different settings. The finding base on this research showed that the attitudes and motivation of the young foreign language learners are not stable learner characteristics but change over time, creating layers of complexity.

Quadris (2012) has carried out his research work on EFL learner's motivation in learning a foreign language. His objectives were leak EFL learner's motivation in learning a foreign language from a theoretical approach. He explained different definitions of motivation of concept, definition of different kinds of motivation, the importance of motivation, factors that influencing motivation. At the end of research, the researcher summarized the research and focus on motivation of learners in learning a foreign language.

Atta and Jamil have carried out research on "effects of motivation and parental influence on the educational attainments of students at secondary level" in order to understand is motivation and parental influence have effect on the educational attainments of the students at secondary level or have not, in Order to measure student's level of motivation and parental influence. The result showed that there is a significant and positive effect of motivation and parental influence on the educational attainments of the student's at secondary level. The educational attainment of those students who were under the influence of their parents and motivated is better.

\section{What Is Motivation?}

Motivation is defined differently according to different perspectives. According to behaviorist, motivation is an anticipation of reward in order to acquire positive reinforcement. In this view our acts are at the mercy of external forces.

In cognitive terms, ,based on Maslow opinion(Maslow, 1970), motivation has more emphasis on the individual's "decisions, the choices people make as to what experiences or goals they will approach or avoid, and the degree of effort they will exert in that respect'. Some cognitive psychologists see underlying needs or drives as the compelling force behind our decisions (Maslow, 1970).

According to constructivists, each person is motivated differently based on his or her unique situation. However, these motivations are always done within combine of cultural and social and cannot be separated from the society. Abraham Maslow (1970) viewed motivation as a construct in which ultimate attainment of goals was possible only by passing through a hierarchy of needs, which were solidly grounded in community, belonging and social, etc.

Maslow (1970) saw motivation as dependent on the satisfaction, first of fundamental physical necessities then of community security, identity and self-esteem, the fulfillment of which finally leads to self -actualization. In his view, (Maslow (1970)), motivation was dependent on the satisfaction of fundamental physical necessities and then of community security, identity, self-esteem, which finally leads to self-actualization.

\section{KINDS OF MOTIVATION}


In the world, people have different reasons for studying a foreign language: some study a language and enter to learn language just for practical reasons, while others are interested in a particular language and its speakers and cultures as well. For many language learners, learning a language is only a means for an academic degree. Gardner and Lambert (1972) define integrative and instrumental motivation. Falk (1978) believed that the successful students in the learning of a target language are those who had a desire to become familiar with the society in which the target language was used; this kind of motivation is known as integrative motivation.

Integrative motivation is a key component in assisting the students to improve some level of proficiency in the language, when he/she becomes a resident in a new society that uses the target language in its social interaction. A learner can be one of the members of a community in which the target language is spoken by using integrative motivation. It is also theorized "integrative motivation typically underlies successful acquisition of a wide range of registers and a native like pronunciation" (Finegan, 1999, p.568).

The hypothesis of the Gardner (1982) was about integrative motivation. He believed that oriented learners were more persistently and intensely motivated than other learners. In his view an integrative oriented learner had a stronger desire to learn the language and had more positive attitudes towards the learning situation, and was more likely to expand more effort in learning the language. Gardner believes that the interactively motivated students and learners are more active in language classes, and they are more successful in learning a second and foreign language. There students are more eager to participate in other society, and to interact with members of that community.

\section{A. Instrumental Motivation}

Instrumental motivation refers to when we acquire a language just for instrumental goals or it means to learn a language with non-interpersonal purposes such as to pass an exam or just to have a career. As the researcher believes, Learners with an instrumental motivation want to learn a language because of a practical reason such as getting a jobs or getting into college.

Spolsky (1989), it is worth mentioning that an instrumental motivation is referred to a specific goal. If a goal is continuous, it seems possible that an instrumental motivation would also continue to be active. To a considerable extend, this is the point made by Spolsky (1989), in his analysis of the role that economic factors could play in promoting second language acquisition in some contexts.

These two orientations (integrative/ instrumental) are not mutually exclusive. Some learners learn better if they are interactively oriented, while others are more successful if they are instrumentally motivated and some learn better if they take the advantage of both orientations (Spolsky, 1989).

Deci and Ryan (1985) put forward intrinsic/extrinsic motivation theory. According to Rotter (1966), intrinsic/ extrinsic motivation is related to the term locus of control.

\section{B. Intrinsic Motivation}

Considering Rotter (1966), if a person places responsibility for his/her life within self, she/he has internal locus of control and is self - motivated character. In order to achieve internal locus and self- motivation, one should be eager to give up the security of making excuses and to take responsibility of all her/his decisions and actions (csikszentmihalyi, 1975, deci,1975, deci \& Ryan, 1985). Intrinsic motivation is a motivation which is in the inner of the students. An intrinsically motivated student studies because he/she wants to study and The material is interesting and fun and the student receives some kind of satisfaction from learning (deci, 1975). In intrinsic motivation there is no reward except the activity itself, It means that the essence of motivated action that is, sense of autonomy and the desire is self initiating and self - regulating (deci \& Ryan, 1985).

\section{Extrinsic Motivation}

If a person places the responsibility on others and on circumstances outside self, she/he has external locus of control (dornyei, 2000). In fact Extrinsic Motivation refers to motivation that comes from outside of an individual, its factors are external or outside rewards such as money or grades and these rewards provide satisfaction and pleasure that the task itself may not provide (dornyei, 2000).

A person who is motivated extrinsically works on a task that there is little or no interest in it, there is no good satisfaction from learning. The rewards can be something as minor as a smiley face to something major like fame or fortune (dornyei, 2000). Extrinsic motivation does not mean, how- ever, that a person will not get any pleasure from working on or completing a task, It just means that the pleasure they anticipate from some external reward will continue to be a motivator even when the task to be done holds little or no interest. For example an extrinsically motivated student, may dislike an assignment, may find it boring, or may have no interest in the subject, but the possibility of a good grade will be enough to keep the student motivated in order for him or her to put forth the effort to do well on a task (dornyei, 2000).

Maslow (1970) claimed that intrinsic motivation is clearly superior to extrinsic, because learners are motivated to achieve "self-actualization". Based on his idea, once basic physical, safety, and community needs are met, regardless of the presence or absence of extrinsic reward we will strive for self-esteem and fulfillment. One of the most effective ways to help students is to free them from the control of rewards (Bruner, 1966). In some cases intrinsic and extrinsic 
motivation may overlap to some degree, because one may be motivated from both an inside source and outside one at the same time. Obviously both kinds of motivation play important roles in learning foreign language.

\section{FACTORS INFLUENCING MOTIVATION}

According to Gardner many factors influence motivation and acquisition of second language. These factors include personality variables, attitudes towards the social and cultural milieu, and linguistic and nonlinguistic outcomes of the learning experience. At follow I discuss these factors in brief. Personality variable is one of these factors. Many believe that there is a positive relationship between personality characteristics and learning a second language successfully. While different students have different types of useful characteristics.

Giles and Copland (1991) believe that the individual differences such as intelligence, aptitude, motivation and anxiety can influence the acquisition of the second language. These variables depend on the context which learning takes place. For example, in a formal setting, intelligence and aptitude play an important and basic role in learning, while in an informal setting exert a weaker influence. Another factor which influences motivation is attitudes which learners have.

Different beliefs of individuals about other cultures and languages have different impacts on second language acquisition. Gardner suggests when expectations, combined with attitudes toward the second language and its culture, they form the basis of an individual's attitude towards language learning at general (1979, Cited in Skehan, 1993). Linguistic outcomes are another factor which influences motivation, which refer to real language knowledge and skills. Non - linguistic out- comes reflect an individual's attitudes, values and beliefs, usually towards the second language community or society. Individuals who integrate both outcomes of the learning experience will attain a higher degree of second language proficiency (Ellis, 1997).

Foreign language teachers and researchers come to the basic idea that individual students prefer modalities of learning. Consequently, when learners have some freedom to choose one way of learning or another, they do better than those who find themselves force to learn in environments where a learning style, is imposed as the only way to learn. So the styles of learning affect motivation. One of the positive views of the initiators of humanistic approaches to learning is that teachers should adapt their programs with the objectives of their students and the needs of the area where they are teaching. Though, this is not always easy, in this case, student's learning styles is a great help in motivating them to learn.

Positively motivated students are more pleasant to teach, prepare more carefully for class, participate more actively in class, and achieve more than negatively motivated students. For enhancing positive motivation teachers have to attend to other classroom factors such as classroom management, Teacher-student affiliation and methods of instruction. Motivating students is not easy. Oliva (1972) states that students are motivated to learn when they;

1. Deal with material geared to their level.

2. See purpose in their activities and study.

3. See their studies as important.

4. Are given a demanding work.

5. Live in a secure environment.

6. Feel the learning is for them and not for the teacher.

7. Work with interesting material.

8. Experience more success than failure.

9. Have the opportunity to express their psychological needs for success, recognition, and approval.

10. Conceive of themselves as capable individuals.

11. Have some opportunity to make decisions, enter into the planning, and feel responsibility for participating.

Fishman (1984) maintains that an important factor in motivation to learn a second language is its "socio-functional" validity. From the student's perspective, learning a second language may or may not be worthwhile, depending upon its social reality for the learner, language learning has an important social function, when the learner has a reason for using the acquired knowledge and skills to communicate with other people of importance in his or her environment. In other word, when no out-of-class validity exists, language learning loses its functional relevancy, and lack of motivation becomes a problem. Teachers should recognize that for improving motivation they will be dealing whit cognitive, affective, social and perhaps even psychomotor variables. Below I list some of the recommendations which are offered as positive suggestions for improving student's achievement motivation.

\section{Cognitive}

a. Give the students feedback as to their progress (Klausmeier and Ripple, 1971).

b. Use resumes and review sessions to help students organize the material in their mind (Oliva, 1972).

c. Use class work that requires the use of previously learned material (Gage and Berliner, 1975).

\section{Affective}

a. Develop a system of rewards for good work or good conduct be prepared poor work or misconduct as necessary (Klausmeier and Ripple, 1977).

b. Give assignments that appeal to the students, that they can accomplish, and that will improve their class performance the following day (Olive, 1972). 
c. Use simulations and learning games in appropriate situations to enhance learning and heighten motivation (Gage and Berliner, 1975).

\section{Social}

a. Discuss desired "prosocial" behavior with the class (Klausmeier and Ripple, 1971).

b. The teacher should comprehend the power relationships operating in the classroom. He has various powers inherent in his position as the teacher: reward, coercive, referent and expert power. These powers give the teacher the advantage over the students. At the same time, he should realize that the student also have a degree of social power that can be employed individually and collectively to influence teacher behavior (Gage \& Berliner, 1975).

\section{CONCLUSION}

Foreign language acquisition is a complicated process, which involved different factors. The personality factors, especially non-intelligence factors, such as motivation, attitude, character, etc., are the most important ones, among them, apparently, motivation is the key to learning (Dahmardeh, M., \& Hunt, M., 2012). To conclude, we receive in the fact that motivation is an important variable when we examining the successful of the second language learning (Mao, Z., 2011). One of the best step for facilitate learning for learners is to inform learners about needs of motivation in learning. Students should be motivated in different ways, because different students with different characteristics need different types of motivation. In classroom motivation can be provided by other students, in my opinion in this way students become more motivated. In addition to factors which influence student's motivation and are discussed in this paper, teachers should consider other factor, according to their classroom environment, student's aptitude, and course goals and so on.

\section{REFERENCES}

[1] Abdelrahim, I., \& Humaida, I. (2012). Research on: Motivation to Learn English among College Students in Sudan.English Language Teaching, Vol-5, pp-49-56.

[2] Afful-Broni, A. (2012). Relationship between Motivation and Job Performance at the University of Mines and Technology, Tarkwa, Ghana: Leadership Lessons. Scientific Research Journal, 6 (3), pp-309-314.

[3] Akolkar, A. (2012). A comparative study of Achievement Motivation and Mental Health among higher secondary students. Review of Research Journal. Vol-1, pp-1-4.

[4] Csikszentmihalyi,M. (1975).beyond boredomand anxiety.san francisco:jossey-bass.

[5] Dahmardeh, M., \& Hunt, M. (2012). Motivation and English Language Teaching in Iran. Studies in Literature and Language, 7 (5), pp-36-43.

[6] Deci, E. (1975).intrinsic motivation.new york:plenum.

[7] Deci, E., \& Ryan, R. (1985). Intrinsic motivation and self-determination in Human Behavior. New York: Plenum Press.

[8] Djigunović, J. M. (2012). Attitudes and Motivation in Early Foreign Language Learning. c e p s Journal. Vol-2, pp-55-74.

[9] Dornyei,z. (2000).motivation.in M.byram(ed).Routledge encycolopedia of language teaching and learning(pp.425-4320).new yourk:Routledge.

[10] Ellis, R. (1997). The study of second language acquisition. Oxford: Oxford University Press.

[11] Falk, J. (1978). Linguistic and language acquisition: A survey of basic concepts and implication (2 ${ }^{\text {nd }}$ Ed.). John Wiley and Sons.

[12] Finegan, E. (1999). Language: Its structure and use (3th ed., p. 568). Harcourt Brace.

[13] Fishman, J. (1984). Sociolinguistic perspectives on Second-language acquisition. Thirteenth university of Wisconsin Milwaukee Linguistic symposium. Milwaukee, Wisconsin, March 23-24.

[14] Gage, N.L., \& Berliner, D.C. (1975) Educational psychology. Chicago: Rand McNally.

[15] Gardner, R.C., \& Lambert, W.E. (1972). (1982). Attitudes and motivation in second-language learning. Rowley, Mass; Newbury House.

[16] Gardner, R.C. (1982). Language attitudes and language learning. In E. Bouchard Ryan \& H. Giles (Eds.), Attitudes towards language variation (pp.132-147). Edward Arnold.

[17] Giles, H., \& Coupland, N. (1991). Language: Contexts and consequences. Open University Press.

[18] Jamil, A., \& Atta, M. (2012). Effects of Motivation and Parental Influence on the Educational Attainments of Students at Secondary level. Academic Research International.

[19] Klausmeier, H.J., \& Ripple, R.E. (1971). Learning and human abilities: Educational psychology. (3 ${ }^{\text {rd }}$ Ed.) New York: Harper \& Row.

[20] Mao, Z. (2011). A Study on L2 Motivation and Applications in Reading Class in Senior High School. Theory and Practice in Language Studies. Vol-1, pp-1731-1739.

[21] Pourhosein Gilakjani, A; Leong, L; Sabouri, N. (2012).A Study on the role of motivation in foreign language learning, I.J.Modern Education and Computer Sceince. Vol-pp-9-16.

[22] Rotter, J.B. (1966). Generalized expectancies for internal versus external; control of reinforcement. Psychological Monographs, 80.

[23] Skehan, p. (1993). Individual differences in second language learning. Edward Arnold.

[24] Spolsky, S. (1989). Conditions for second language learning. Oxford: Oxford University Press.

[25] Tuan, L. (2012). An Empirical Research into EFL Learners' Motivation. Theory and Practice in Language Studies, Vol-2, pp430-439.

[26] Vasant, Sh. (2012). The Relationship between Academic Achievement and motivation in adolescents. Indian Streams Reserach Journal. Vol-2, pp-1-4. 


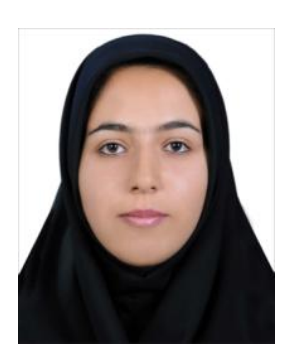

Seyedeh Sara Jafari received her B.A. degree in TEFL from Sheikhbahaee University, Isfahan, Iran. She continued her M.A. in TEFL at Azad University, Abadeh, Iran. She has been teaching English to Iranian EFL learners at several language institutes for more than four years. She has also taught General English courses at Azad University of Safashahr, Fars. Now, she is the deputy of research department of kharazmi-international institute in safashahr, Fars. As a researcher, she has contributed to some local and international journals such as national conferences in Iran, journal of English teaching in Iran, and Journal of Language Teaching and Research. Her main areas of interest include second language acquisition, first language acquisition, language teaching methodology, the role of affective variables in language teaching, psycholinguistic and contrastive analysis. 